\title{
Example of an innovative initiative for education in thermal energy storage: INPATH-TES project
}

\author{
Gabriel Zsembinszki and Luisa F. Cabeza
}

GREiA Research Group, INSPIRES Research Centre, University of Lleida, Pere de Cabrera s/n, 25001 Lleida (Spain)

\begin{abstract}
Following the EC SET-Plan Education and Training Roadmap, the goal of INPATH-TES is to create a network of academia, research institutes and small and medium-sized enterprises (SMEs) to implement a joint $\mathrm{PhD}$ programme on Thermal Energy Storage (TES) technologies. The project consortium consists of 22 partners from academia, industry and SMEs from 14 different countries. The final result of such a network is to educate professionals on these technologies for the European research and industry institutions. Some of the main challenges identified so far consist of the development of the programme, the implementation of the programme in each country/institution, and to ensure the continuity of the programme after EU funding ends.
\end{abstract}

Keywords: Thermal energy storage, PhD programme, e-learning

\section{Introduction}

According to the European Commission (EC) SET-Plan Education and Training (E\&T) Roadmap (JRC Coordination, 2014), there is a need for more efficient education in the area of thermal energy storage (TES). To meet the needs and fill the gaps identified by the SET-Plan E\&T Roadmap, the project "Innovative Pathway for $\mathrm{PhD}$ research in Thermal Energy Storage" (INPATH-TES), coordinated by the University of Lleida, Spain, was launched in May 2015 (www.inpathtes.eu). The project is funded within the framework of the research and innovation programme Horizon 2020 by the EC.

The goal of INPATH-TES is to create a network of academia, research institutes and small and medium-sized enterprises (SME) to cooperate in defining and implementing a joint $\mathrm{PhD}$ programme on TES technologies. The final result of such a network will be the qualification of professionals for European research and industry institutions interested in hiring personnel with expertise in TES technologies. The specific objectives and outcomes of INPATH-TES project are:

- to establish a unique $\mathrm{PhD}$ programme in the field of TES starting year 2017,

- to develop at least 20 ECTS equivalent common training modules,

- to develop four technology oriented $\mathrm{PhD}$ courses,

- to establish one annual joint workshop for $\mathrm{PhD}$ students,

- $\quad$ to aim at graduating $28 \mathrm{PhD}$ students per year at year 2021, and

- to exchange at least $14 \mathrm{PhD}$ students per year between industry and academia.

The INPATH-TES consortium consists of 22 partners from 14 European countries, and has the presence of 14 universities, 3 research institutes, 3 industries, and 2 SMEs. Currently, they are the core of a future larger network of excellent R\&D institutions, and industries for co-funding and industrial placement, sharing infrastructure capacities, and enhancing mobility of students. 


\section{Approach for the PhD programme in TES and main results}

The INPATH-TES work plan is divided in six work packages, being either coordination or support activities. Main coordination activities contain the development, maintaining and updating of the $\mathrm{PhD}$ programme in TES and the implementation of the $\mathrm{PhD}$ programme. Main support activities are stakeholder involvement, expansion of partnerships, framework for monitoring and evaluation of INPATH-TES as well as intellectual property rights, and regulatory issues.

A total of curriculum 14 courses are currently being developed by the consortium that can be implemented from a global perspective in ECTS awarding institutions. The courses can be grouped as follows:

- Basic common PhD courses: Research and PhD, Introduction to thermal energy storage, Thermal energy storage materials, Testing and characterisation of thermal energy storage materials, and Heat and mass transfer and sizing of energy storage devices.

- Common technology specialisation courses: Thermal energy storage applications for buildings, Demand side management concepts and energy storage, Large scale and industrial energy storage, and Energy policy and market development.

- Research management, dissemination, and communication courses ("soft skills"): Intellectual property and patenting ideas, Idea to product development, Dissemination and communication of $\mathrm{R}+\mathrm{D}+\mathrm{I}$, Funding of research and project management, and Management and entrepreneurship.

\subsection{Description of the courses}

\subsubsection{Research and $\mathrm{PhD}$}

The main objective of this course is to introduce the students to the basic aspects related to the scientific method, and provides the students with the details on the concepts of research, development and innovation $(\mathrm{R}+\mathrm{D}+\mathrm{I})$. Specifically, the course provides an introduction to the different research methods and exposes the differences between the definition of $\mathrm{PhD}$ and industrial $\mathrm{PhD}$. Concepts such as Responsible Research and Innovation (RRI), management of the research data, and the Intellectual Property Rights (IPR) are also dealt with in detail. The students also have the opportunity to learn how to correctly write a CV (academic and industrial one) and supporting statements.

\subsubsection{Introduction to TES}

The course will introduce students to thermal energy storage (TES), from thermophysical properties of materials used in TES systems to their implementation into the energy system. Thus, it will introduce the energy system and policy drivers, describing the technologies that can be used for storing energy, and focusing on fundamentals of thermal energy storage, its technologies, and its role in the energy system, while providing details on thermodynamic properties of materials. The learning philosophy of this course is to provide students enough information in order, for them, to be able to analyse a problem related to thermal energy storage and have a first idea on how to solve it by TES.

\subsubsection{Thermal Energy Storage Materials}

The purpose of this course is to provide an overview of thermal energy storage materials and their properties. It will also introduce a selection methodology as a tool for selecting TES materials performing the best for a certain application. Numerical models will be introduced for design and calculation of composite structures including TES materials, in order to perform an optimal selection regarding energy efficiency. Numerical models at micro/nano-scale for TES materials can provide better understanding of the heat and mass transfer phenomena on small scales. This knowledge can be applied to the design of new energy storage materials. A continuous learning philosophy is adopted in this course, with emphasis on problem solving through application of thermal engineering fundamentals - energy balances and thermodynamics. This course will be linked to other courses such as building or industrial applications.

\subsubsection{Testing and characterisation of Thermal Energy Storage Materials}

The course focuses on the characterization of energy storage materials and on the methods that could be used for testing them. It will provide the theoretical background and standard of characterization, describing also the 
instrumentation and the parameters that have to be measured. Thermal and structural characterization technologies have been subdivided in conventional and "in house". Such technologies are the objects of the lessons of the course with the aim to offer a complete overview on: Differential Scanning Calorimetry (DSC); Thermogravimetric Analysis (TGA); T-history methodology and stability analysis for heterogeneous materials; technologies for measuring morphological, structural and specific solid properties, thermal diffusivity, thermal conductivity, thermal expansion, rheological properties, volatility and vapour pressure. Lab scale, experimental and in-situ procedures for thermal response, compatibility, flammability and mechanical testing will be given also.

\subsubsection{Heat and Mass Transfer and Sizing of Energy Storage Devices}

This course provides the INPATH-TES students with basic and advanced knowledge in heat transfer. It addresses such topics as multi-dimensional heat transfer, mass transfer, heat transfer with phase change, thermal design and component modelling. It is envisioned that since the $\mathrm{PhD}$ programme allows enrolling students with very different background, their entrance level knowledge in heat transfer may significantly vary. For this reason, the learning material includes such very basic items as fundamental heat transfer modes, thermal properties of materials, and heat transfer enhancement. On the other hand, students with an appropriate background would proceed directly to the lessons on basic numerical methods for thermal problems, analysis and modelling of heat transfer with phase change, and study of specific effects related to heat transfer in phasechange materials. Mass transfer by diffusion and convection is included as the theoretical basis for thermochemical energy storage. An advanced student will also acquire broad knowledge and practical tools in principles of thermal design, modelling and optimization of heat transfer equipment in general and sensible, latent and thermochemical energy storage devices, in particular.

\subsubsection{Intellectual Property and Patenting Ideas}

The purpose of this course is to provide the students enrolled in the INPATH-TES PhD programme with all fundamental aspects of Intellectual Property (IP) in general, and of patents in particular. The first part of the course is designed to provide an overview of IP and the reasons why it is considered an important economic and cultural asset in today's life and economy. Another important subject of the first part of the course is devoted to the definition of the dissemination, exploitation and communication plan. The second part of the course focuses on some basics concepts regarding patents, such as the relevant parts of the patent system and how to make use of patent information to encourage innovation and economic growth, patent classification, and the main tools available for patent information search. Besides this, the course also explains the different ways to apply for a patent, and presents some relevant case studies for a better understanding of the theoretical information presented.

\subsubsection{Idea to Product Development}

The objective of the course is to provide the methodology required to develop a product starting from the preliminary idea. The structure of the course starts with an introduction (with the need for innovation), then it describes the idea generation, idea screening, idea development and testing, followed by the business analysis, finishing with the technical implementation of a new idea.

\subsubsection{Dissemination and Communication of $R+D+I$}

This course aims at providing the students sufficient skills and information needed to locate and successfully apply for suitable sources of research funding, and to introduce them to the basics of project management, dissemination, exploitation and communication. Specifically, the course presents the different types of funding available and where these sources of funding can be found, how networking can help in locating funding, how to prepare and write a proposal, and how proposals are evaluated. Furthermore, the course also presents the different stages of the lifecycle of a project and explains the main skills required in managing a project. Finally, the purpose and definition of the research dissemination, exploitation and communication plan are also provided.

\subsubsection{Funding of Research and Project Management}

This course aims at providing the students sufficient skills and information needed to locate and successfully apply for suitable sources of research funding, and to introduce them to the basics of project management, 
dissemination, exploitation and communication. Specifically, the course presents the different types of funding available and where these sources of funding can be found, how networking can help in locating funding, how to prepare and write a proposal, and how proposals are evaluated. Furthermore, the course also presents the different stages of the lifecycle of a project and explains the main skills required in managing a project. Finally, the purpose and definition of the research dissemination, exploitation and communication plan are also provided.

\subsubsection{Management and Entrepreneurship}

This course provides an introduction to Management and Entrepreneurship for course participants with a technical background. The topics covered in this course are prototype to market roadmap (business ideas), business planning (innovation concept), entrepreneurship (start-up company), managing firms for growth, and building soft skills in management and entrepreneurship. By the end of this course, participants will be able to generate business ideas, assess opportunities, formulate business strategies, find their first customers, procure funding for start-ups and manage firms for growth. Soft skills such as teamwork, leadership and communication for management and entrepreneurship are covered as well.

\subsubsection{Thermal Energy Storage Applications for Buildings}

In this course, the main building integration strategies of TES systems as passive and active solution for energy saving and indoor thermal comfort conditions are introduced and discussed. The key evaluation methodologies, e.g. experimental assessment and modelling-simulation approach, are also presented and deeply analysed. Then, the most significant research contributions are described and the uttermost promising future trends are outlined. Finally, the student is driven to select the proper TES solution with varying the main constraint of several research problems and also the district scale application is discussed, in cooperation with other two courses of the same PhD programme (Course 12 and Course 13).

\subsubsection{Demand Side Management Concepts and Energy Storage}

Demand side management (DSM) is based on two essential features, namely energy efficiency and of increasing importance, the role of demand side response. Energy efficiency is essential if we are to deliver zero carbon and low energy solutions for society. Changes to human behaviour and control systems are increasingly proving to be critical if energy savings, as a result of technological development, can be maximised. Often technology improvements are let down by the human involvement and hence it is important that those involved with research into the development and implementation of technologies understand demand side management. Demand side response addresses variable electricity and heat load management, whether driven by variable renewable energy or batch/cyclic demand and supplies. The course will cover the subject at macro - city level, down to buildings. It will outline legislative and incentive programmes, discuss the financial aspects and conclude with case studies of DSM.

\subsubsection{Large Scale and Industrial Energy Storage}

This course aims at providing the students with information about the use of thermal energy storage technologies in large-scale and industrial applications. The course begins with an introductory overview of examples of the integration of thermal energy storage in production and energy facilities, specifically in energyintensive industries, concentrating solar power, and district heating and cooling. The students will be introduced to recent research progress in terms of innovative materials, container designs and concepts for systems integration for large-scale TES. Specific demonstration and operational, real-world projects as well as collection and analysis of in-field performance data will be discussed in detail. Different numeric simulation exercises give an introduction to the computer aided TES design and integration using realistic scenarios. The course will delve into environmental and economic aspects of large-scale TES installations, specifically introducing the use of LCA, LCC and further analyses in these studies, and will close with several real-world examples of applications in large-scale thermal energy storage. Common issues with industrial installations will be presented, including the scalability of $R \& D$ results.

\subsubsection{Energy Policy and Market Development}

The energy policy and market development course takes a holistic approach in looking at how thermal energy storage can solve issues identified at EU policy level. It commences by providing insights into energy policy 
with particular reference to renewable energy policies, and examines this further by considering "good" and "poor" policies. Then in a heuristic fashion, it looks at the theory and real-life examples of how market development tools can be used to identify and develop new opportunities for TES in the context of energy efficiency and renewable energy technology policies. The course also examines how best to inform policy through key skills such as networking, influencing and communication, and how this can be enabled by being close to the customer and aware of predicted future market developments.

Each of these courses is composed of various topics, and each topic is then composed of different lessons. The lessons can then be "tailor-packaged" to meet the needs of each of the $\mathrm{PhD}$ supervisors for their $\mathrm{PhD}$ candidates. The developed learning material is implemented in the constructive alignment perspective in the EIT (European Institute of Innovation and Technology)/KIC InnoEnergy pedagogical methodology of student-centred learning, aligned teaching, and active learning (Biggs and Tang, 2011).

\subsection{Online learning platform}

An e-learning repository platform has been commissioned to host all the learning materials that will be delivered in the PhD curricula. The pedagogical methodology in student centred learning consists of careful design by the teachers of the intended learning outcomes (ILOs) assessed with the achieved learning outcomes (ALOs) assessment questions (EIT handbook, 2016). The online learning platform self-learning section consists of recorded learning videos, recorded lectures, automatically corrected exercise, remote lab, filmed study visits and online literatures. Randomized automatically corrected calculation exercises are to be programmed so that students may test their skills and knowledge at their convenience.

Based on the specific content generation and delivery needs of the project, as well as the demands of the consortium's partners, the following main functionalities have been delivered: set of tools for content creation and co-creation between partners; server for content storage and indexation; tools for application of the agreed pedagogical methodology; system for achieving the 3 stages material review (content, methodology, IT) process; front-end, autonomous, self-operating content delivery system which allows the student to follow the courses with no needed for the professor to intervene for ensuring the due learning process; tracking mechanism of student progress, including completion of exercises and results, plus generation of a report; generation of certificate after completion of each course's lesson; complimentary online manual and instructional videos for solution understanding and operation.

\subsection{Web-based platform}

The internet has become a powerful tool for reaching a wide range of groups of people and websites provide the best way of transmitting information. The website has been developed by one of the INPATH-TES partners, TCD, and the domain of the website is www.inpathtes.eu (see Figure 1). The website is a web-based platform designed for external communication and dissemination. This includes a general description of the project along with a more detailed explanation of its specific objective, partners' logos and links to their own websites, a list of project results such as scientific papers and newsletters published during the project life-time, information related to how to enrol on the $\mathrm{PhD}$ programme, a description of the training material that is being developed, information regarding past and future events, links to other relevant European projects and international platforms, and contact information.

Currently, only students belonging to the core members of the INPATH-TES project can register and take lessons from the online learning platform. However, external people from academia or companies may also take courses from the platform in the near future. Enrolments will be possible by filling up the form that will be made available on the project website, and after paying the corresponding fees. 


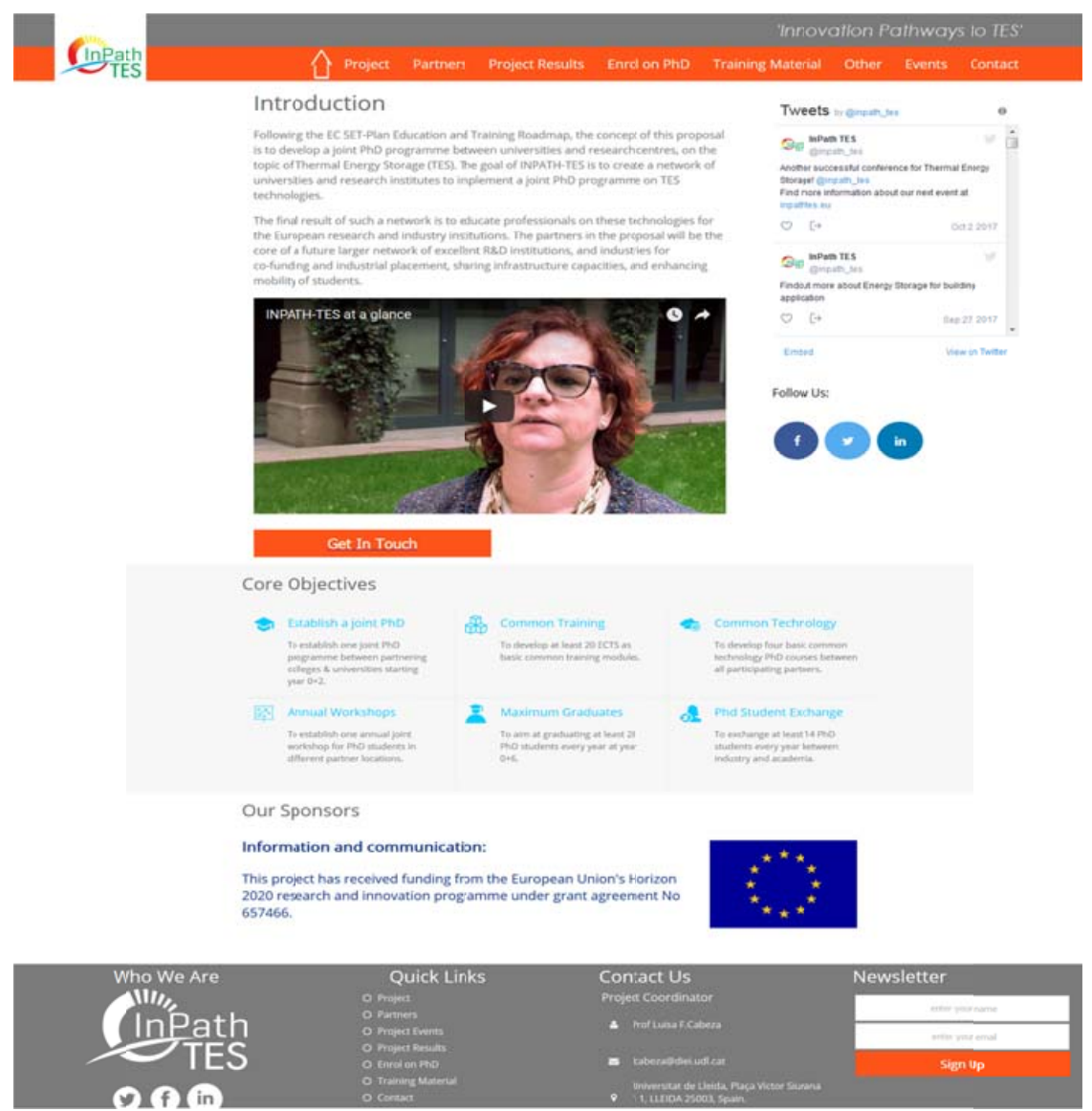

Fig. 1: Image of the website of the project

\subsection{INPATH-TES label}

The students willing to achieve the recognition of INPATH-TES label should contact two partner universities or institutions to join their own doctoral programme under joint $\mathrm{PhD}$ supervision, also called co-tutelle, and achieve the needed milestones. To be awarded the INPATH-TES label, the PhD candidate must fulfil the following requirements:

- $\quad$ To take at least 20 ECTS from lessons within the INPATH-TES programme.

- To perform at least 2 months of internship or secondment to a third partner firom the INPATH-TES consortium for at least 2 months.

- To publish at least 1 scientific journal paper with co-authors from 3 institutions from INPATH-TES consortium.

- To have attended at least one annual INPATH-TES workshop/training school.

\section{Main challenges}

During the development of the project, some difficulties and challenges have been encountered, which can be summarized as follows:

- Development of the programme.

- The implementation of the programme in each country/institution.

- Two levels of work: PhD programme and Master of Science (MSc) programme.

- $\quad$ To ensure the continuity of the programme after EU funding ends.

The main difficulties regarding the development of the programme consisted in the fact that the contents of the proposed curriculum should respond to the needs and gaps identified by the SET-Plan, and at the same time they 
must meet the needs of industry. On the other hand, the presence of many members who are not from academia required additional efforts to successfully adapt and implement the innovative EIT pedagogical methodology into the material developed. Last but not least, the development of a new e-learning platform for hosting the online learning material, and the need for $100 \%$ online assessment activities that does not require the presence of lectures, accounted for an additional degree of difficulty.

With regards to the implementation of the $\mathrm{PhD}$ programme, right from the beginning of the project the consortium collected the main information related to the $\mathrm{PhD}$ programme on the topic of the project in each of the academic institutions participating in the project, as well as others that are in close relationship with research centres also participating in the INPATH-TES project. After collecting all the information, the consortium reached to the conclusion that although there are some common items in all countries regulations, it is very difficult to define a unique implementation agreement for a joint $\mathrm{PhD}$ programme able to fit all requirements from each country. Consequently, the INPATH-TES consortium proposed to carry out doctoral theses in a cotutelle regime as an alternative way to fulfil the main project objectives. A co-tutelle is an agreement on joint supervision at $\mathrm{PhD}$ level (also known as co-tutoring). Such agreements can be reached between the two cooperating universities, the $\mathrm{PhD}$ candidate, and the candidate's supervisors. The co-tutelle agreement regulates enrolment, supervision and the evaluation of the candidate's doctoral degree thesis. The $\mathrm{PhD}$ candidate must be enrolled in both universities, and must have at least one supervisor at each university. Furthermore, the PhD candidate must have a period of stay at both institutions. The thesis must have the logo of both institutions, and the cooperation agreement must be specified. Usually a single public presentation of the thesis is sufficient, which must comply with the rules that are in force at the institution where the presentation is to be given. The $\mathrm{PhD}$ candidate shall receive a diploma from each institution. This kind of $\mathrm{PhD}$ is well recognised in most of the partners' regulations. Therefore, at least 30 bilateral agreements are being negotiated between partner universities, and currently there are already a few students enrolled in co-tutelle PhDs.

Besides the development of a $\mathrm{PhD}$ programme, one of the aims of the project is to also implement a joint Master on TES. There is a big opportunity found in the fact that there is no other master on TES around the world, and that we have developed high quality material during the project. Unfortunately, today it is not possible to have an international joint Master programme outside the Erasmus Mundus programme, therefore the consortium decided to start by implementing a non-university Master programme, but apply in the near future for an Erasmus Mundus. Next step would be to apply for a university Master on TES by one of the universities members of the consortium. Here the biggest challenge would be to ensure its long term sustainability, but this is basically based on the number of students the Master would have each year, and the high specialization of the Master makes it difficult to convince the authorities of its sustainability. Therefore the first step would be to implement a non-university Master on TES at one of the consortium universities with the participation from the other consortium members as lecturers. We expect that after a short period of success of the Master will be the best way to go a step further to get a university master on TES or even a university joint Master on TES with participation of as many partners as possible in a joint-degree.

Finally, one of the main challenges of the project refers to the long-term sustainability of the project, once funding from the EU ends. INPATH-TES has the aim to continue as many years as International Network on TES with a joint-PhD programme and a joint-Master programme. Currently, the consortium is working on the development of a strategy to address this issue. The main problems to address consists in how to provide the funding necessary to meet the costs related to the e-learning platform and for maintaining, updating and reviewing the learning material, and also to establish an appropriate governance structure for the future network. The consortium is considering two possible options: continuing as network, based in one of the partners (now it is the University of Lleida), or creating a non-profit association. In any case, the membership is based on current partners that are the core of the future network of this project on the long-term. For the future sustainability of the project, there will be a membership fee applied to all members. However, the core members will avail a membership discount if they take responsibility of improving, maintaining and updating the learning material. New members are always welcome to join our network, under terms and conditions that will be agreed by the core members. 


\section{Conclusions}

The INPATH-TES project was launched in May 2015 with the main goal to create a network of academia, research institutes and SMEs to implement a joint PhD programme on Thermal Energy Storage (TES) technologies. The proposed $\mathrm{PhD}$ curriculum aims to meet the needs and fill the gaps identified by the SET-Plan E\&T Roadmap, through providing qualified professionals specialized in TES technologies for European research and industry institutions.

A curriculum consisting on 14 courses has been proposed, which are currently being developed by the consortium. Through active engagement with different stakeholder groups in the project, research and market oriented inputs to the $\mathrm{PhD}$ topics were set up in the training courses.

All the leaning material is being implemented in the "flipped classroom" perspective in the EIT/KIC InnoEnergy pedagogical methodology of student-centred learning, aligned teaching and active learning. An elearning repository platform is being developed, which has the functionality of hosting recorded learning videos for efficient learning.

The main challenge that has been identified is the implementation of the joint $\mathrm{PhD}$ programme in each of the participating countries. Although all participating countries in INPATH-TES are within Europe, differences in the regulatory framework for establishment of $\mathrm{PhD}$ programme subsist. In order to overcome this problem, the consortium decided to define different bilateral agreements between partner universities for joint supervision of $\mathrm{PhD}$ students. Another important challenge of the project is how to ensure the continuity of the programme after EU funding ends. By creating further synergies between INPATH-TES and other global organisations and initiatives, extension of the partnership and exchange of students are foreseen.

\section{Acknowledgements}

The authors would like to thank the Catalan Government for the quality accreditation given to their research group (2014 SGR 123). GREA is certified agent TECNIO in the category of technology developers from the Government of Catalonia. This study has received funding from European Union's Horizon 2020 research and innovation programme under grant agreement $\mathrm{N}^{\circ} 657466$ (INPATH-TES). The work is partially funded by the Spanish government ENE2015-64117-C5-1-R (MINECO/FEDER).

\section{References}

Biggs J., Tang C., 2011. Teaching for Quality Learning at University. 4th ed. Milton Keynes: Open University Press.

EIT handbook, 2016. 'Quality for learning' EIT Quality Assurance and Learning Enhancement Model: Handbook for planning, labelling and reviewing EIT-labelled masters and doctoral programmes. Revised ed. European Institute of Innovation and Technology (EIT) as a body of the European Union. Available at [201710-06]: https://eit.europa.eu/sites/default/files/eit_label_handbook.pdf.

JRC Coordination: Georgakaki A., von Estorff U., Peteves S.D., 2014. Strategic Energy Technology (SET) Plan Roadmap on Education and Training. Luxembourg: Publications Office of the European Union. 